\title{
ESTIMATES OF ESSENTIAL NORM OF THE LI-STEVIĆ INTEGRAL TYPE OPERATOR BETWEEN ZYGMUND TYPE SPACES
}

\author{
AMIR H. SANATPOUR
}

Abstract. For an analytic selfmap $\varphi$ of the open unit disc $\mathbb{D}$ and an analytic function $g$ on $\mathbb{D}$, the Li-Stević integral type operator $C_{\varphi}^{g}$ is given by

$$
\left(C_{\varphi}^{g} f\right)(z)=\int_{0}^{z} f^{\prime}(\varphi(\xi)) g(\xi) d \xi .
$$

We give essential norm estimates of the operator between Zygmund type spaces. We also apply our approach in the case of Bloch type spaces.

Mathematics subject classification (2010): 47B38, 30H30.

Keywords and phrases: Essential norm estimate, Li-Stević integral type operator, Zygmund type space, Bloch type space, weighted-type space.

\section{REFERENCES}

[1] P. L. Duren, Theory of $H^{p}$ Spaces, Pure and Applied Mathematics 38, Academic Press, San Diego, 1970.

[2] K. EsmAeILI AND M. LindSTRÖM, Weighted composition operators between Zygmund type spaces and their essential norms, Integr. Equ. Oper. Theory 75 (2013), 473-490.

[3] O. Hyvärinen, M. Kemppainen, M. Lindström, A. Rautio And E. SaukKo, The essential norm of weighted composition operators on weighted Banach spaces of analytic functions, Integr. Equ. Oper. Theory 72 (2012), 151-157.

[4] O. HYVÄRINEN AND M. LINDSTRÖM, Estimates of essential norms of weighted composition operators between Bloch type spaces, J. Math. Anal. Appl. 393 (2012), 38-44.

[5] S. Li AND S. STEVIĆ, Volterra-type operators on Zygmund spaces, J. Inequal. Appl. (2007), Art. ID 32124, $10 \mathrm{pp}$.

[6] S. Li AND S. STEVIĆ, Generalized composition operators on Zygmund spaces and Bloch type spaces, J. Math. Anal. Appl. 338 (2008), 1282-1295.

[7] S. Li AND S. STEvić, Products of Volterra type operator and composition operator from $H^{\infty}$ and Bloch spaces to Zygmund spaces, J. Math. Anal. Appl. 345 (2008), 40-52.

[8] S. Li And S. STEVIĆ, Weighted composition operators from Zygmund spaces into Bloch spaces, Appl. Math. Comput. 206 (2008), 825-831.

[9] S. Li AND S. STEVIĆ, Integral-type operators from Bloch-type spaces to Zygmund-type spaces, Appl. Math. Comput. 215 (2009), 464-473.

[10] S. Li AND S. STEVIĆ, On an integral-type operator from $\omega$-Bloch spaces to $\mu$-Zygmund spaces, Appl. Math. Comput. 215 (2010), 4385-4391.

[11] S. Li AND S. STEVIĆ, Products of composition and differentiation operators from Zygmund spaces to Bloch spaces and Bers spaces, Appl. Math. Comput. 217 (2010), 3144-3154.

[12] M. LindSTRÖM AND A. H. SANATPOUR, Derivative-free characterizations of compact generalized composition operators between Zygmund type spaces, Bull. Aust. Math. Soc. 81 (2010), 398-408.

[13] B. MACCluer AND R. ZHAO, Essential norms of weighted composition operators between Blochtype spaces, Rocky Mountain J. Math. 33 (2003), 1437-1458.

[14] J. S. MANHAS AND R. ZHAO, New estimates of essential norms of weighted composition operators between Bloch type spaces, J. Math. Anal. Appl. 389 (2012), 32-47. 
[15] A. Montes-RodrígueZ, Weighted composition operators on weighted Banach spaces of analytic functions, J. Lond. Math. Soc. 61 (2000), 872-884.

[16] S. Ohno, K. Stroethoff AND R. Zhao, Weighted composition operators between Bloch-type spaces, Rocky Mountain J. Math. 33 (2003), 191-215.

[17] A. H. SANATPOUR AND M. HASSANLOU, Essential norms of weighted composition operators between Zygmund-type spaces and Bloch-type spaces, Turkish J. Math. 38 (2014), 872-882.

[18] S. STEVIĆ, On an integral operator from the Zygmund space to the Bloch-type space on the unit ball, Glasg. Math. J. 51 (2009), 275-287.

[19] S. STEVIĆ, Integral-type operators from a mixed norm space to a Bloch-type space on the unit ball, Sib. Math. J. 50 (2009), 1098-1105.

[20] S. STEVIĆ, On an integral-type operator from Zygmund-type spaces to mixed-norm spaces on the unit ball, Abstr. Appl. Anal. (2010), Art. ID 198608, 7 pp.

[21] S. UEKI, On the Li-Stević integral type operators from weighted Bergman spaces into $\beta$-Zygmund spaces, Integr. Equ. Oper. Theory 74 (2012), 137-150.

[22] W. YANG, Y. LUO AND X. ZHU, Differences of generalized composition operators between Bloch type spaces, Math. Inequal. Appl. 17 (2014), 977-987.

[23] X. ZHU, A new characterization of the generalized weighted composition operator from $H^{\infty}$ into the Zygmund space, Math. Inequal. Appl. 18 (2015), 1135-1142. 